\title{
Hospital Readiness for COVID-19: The Scenario from India with Suggestions for the world
}

\section{Mandalam S. Seshadria and T. Jacob John ${ }^{\mathrm{b}}$}

${ }^{a}$ MD, PhD, FRCP, Former Professor of Medicine \& Endocrinology, Department of Endocrinology Diabetes \&

Metabolism, Christian Medical College \& Hospital, Vellore; Consultant Physician \& Endocrinologist, Honorary

Medical Director, Thirumalai Mission Hospital, Vanapadi Road, Ranipet, India

b PhD (Virology), FRCP (Paediatrics), Former Professor\& Head, Department of Clinical Virology, Christian Medical

College \& Hospital, Vellore, India

\begin{abstract}
Lessons learned from Italy regarding hospitals and health care facilities as important sources of disease spread for COVID-19, and ways to mitigate this in India and other countries.
\end{abstract}

Key Words: COVID-19, hospitals, mitigation, low income countries.

We have learned that recently, in two hospitals in India, emergency surgical procedures were performed on patients and healthcare personnel got infected with SARS-CoV-2. These surgical patients developed COVID-19 pneumonia in the postoperative period, and succumbed. In these hospitals, a large number of health care professionals got infected. This had led to a lock down and containment situation of these hospitals. These incidents have provided many important lessons for the medical profession, other healthcare workers, administrators, and health ministries.

If asymptomatic individuals during the incubation period develop COVID-19 in the postoperative period, there are only 2 possibilities: 1. Their infection was nosocomial; or 2. They were already infected on presentation. In either situation community level spread is occurring. In option one it would represent silent

April 2020. Christian Journal for Global Health, 7(1) infection in medical staff or other admitted patients.

\section{The Experience in Italy}

Italian doctors, after their heart-rending experiences with COVID-19, made a plea in NEJM Catalyst; their article carries the following messages for the rest of the world in the approach to COVID-19 pandemic ${ }^{1}$ :

1. The virus is exploiting centralized health care systems of the current era in a large number of countries.

2. Once you keep admitting very sick patients with high viral load, the hospital becomes a reservoir of the virus. Health care personnel acquire infection and unwittingly become vectors, who spread the infection to their patients and this leads on to further 
community spread. So, hospitals become hotbeds of SARS-CoV-2 infection.

3. A good number of health care professionals contract and some succumb to the infection they contracted in the hospital.

4. Physicians generally are skilled in treating individual patients and often make decisions in the interest of the patient as a whole rather than one symptom or abnormality. For example, in a difficult to control diabetic the physician may accept suboptimal control of blood sugars in order to avoid hypoglycaemia which can be life threatening. Similarly, in a pandemic, the way the medical profession should respond is to do their level best to consider the population as a whole and keep the population healthy. They need to think differently in order to achieve this. This approach is likely to reduce overall spread of COVID-19 and reduce overall mortality.

5. If you do not follow this approach, the human toll becomes huge as in Italy, Spain, and the US.

6. They recommend home based care as far as possible (mild and moderate COVID 19 cases, including those who have early COVID-19 pneumonia who need oxygen with home oxygen if needed, under the care and supervision of the family physician. This will minimize potential for contamination of hospitals.

7. There is a place for a fully isolated, wellequipped COVID-19 centres with all tertiary facilities manned by a committed team to take care of those who need positive pressure ventilation.

\section{An Approach to Hospital-based}

\section{Mitigation}

There is an old saying originating from the Bible (Luke 4:23) "Physician, heal thyself!" In

April 2020. Christian Journal for Global Health, 7(1) the current COVID-19 context, this can be rephrased as "Healthcare worker, protect thyself." If healthcare professionals are depleted because of COVID-19 or if the health-care force is demoralised because of personal risk and fear, the situation can become extremely difficult to handle.

How can we handle a catastrophe of this magnitude? How would a humane, caring person in the interest of community justice approach this problem?

1. Ensure alternative avenues of management for chronic non-communicable diseases (NCDs) and restrict regular out-patient department (OPDs). Patients with NCDs are vulnerable people who should not be coming to hospitals potentially contaminated with the virus - for their own safety - but need ongoing management to prevent other causes of morbidity and mortality. Reduce crowding in the hospital, and limit avoidable workload of an already stressed group of healthcare staff.

2. Mobile telephone/telemedicine-based counselling for patients with chronic illness through their usual caregiver with the understanding that if there is a medical emergency, they will have to access a safe hospital not frequented by COVID-19 patients.

3. Home delivery of medications to avoid elderly coming out of their homes. They should be cocooned (reverse quarantined). When necessary, physicians wearing personal protective equipment should undertake home visits - instead of patients coming to hospitals when their illness is of low/moderate severity and not lifethreatening. For example, utilizing mobile services, community acquired infections can be managed at home without a hospital visit. 
4. Multiple hot-lines should be manned round the clock by appropriate health personnel to provide medical advice and counselling. Tertiary level and medical college hospitals must serve as resource centres for practitioners in order to guide them in caring for complex problems, for example, complicated diabetes, hypertension, community acquired infections, etc.

5. Where there is a functioning and reliable system, samples for lab tests should be collected at home, in a dedicated community level blood collection facility, or in a wellequipped mobile van for remote villages. Samples are then transported to the lab and the results of tests communicated to concerned practitioners.

6. Use a syndromic approach to diagnose COVID-19. ${ }^{2}$ Then treat such patients and prevent spread to their family members using appropriate home isolation and other prophylactic measures.

7. PCR or Rapid tests used only for confirming diagnosis when it will affect care, or for welldesigned and ethical studies, so that resources saved can be put to better use.

8. Dedicated ambulance services with adequately protected personnel to carry sick infected subjects to a dedicated COVID centre.

9. Have separate emergency facility for patients with acute respiratory problems. A dedicated team with appropriate personal protective equipment should see these patients. Those needing admission for respiratory failure should be admitted to a separate ICU facility for COVID-19.

10. Major hospitals in either private or public sector can be designated to take on the management of the town and surrounding villages and to set up a model system of

April 2020. Christian Journal for Global Health, 7(1) referral and management in the surrounding areas.

11. Importantly, continue to manage emergencies in non-COVID patients, who need hospital-based care in a separate facility manned by a different set of healthcare personnel. In other settings people are dying from late presentation after being encouraged to stay away from medical facilities.

12. Every patient coming to hospital for any emergency should be considered to be potentially infected with SARS-CoV- 2 and all the staff strive to take suitable precautions (respiratory as for COVID-19 and universal as for HIV).

13. Where safe, non-urgent surgical procedures should be postponed Each patient going for surgery to have a screening PCR on a nasopharyngeal swab and Ig M antibody (as soon as it is available widely) and lab report to be seen before taking up for surgery, similar to the present system in place for hepatitis B, C, and HIV. As even this will miss out a proportion $(\sim 10 \%)$ of SARSCoV-2 infected patients ${ }^{3}$, respiratory precautions as for COVID 19 and universal precautions as for HIV infected patients will be mandatory for every surgical patient and procedure.

\section{Conclusion and Future Hope}

The pandemic will eventually wane when around $50-60 \%$ of the population have been infected and developed immunity. ${ }^{4}$ This may take a few more months. During these crucial months ahead, medical professionals should ensure that they safe-guard their health and at the same time put in their best efforts to tend to the sick and suffering.

We make these suggestions based on our significant clinical experience and understanding 
of the evidence so as to inform the approach of hospitals in India to this pandemic. We also feel that the above suggestions could be applicable to other middle- and low-income countries which are trying to cope with this pandemic.

\section{References:}

1. Nacoti M, Ciocca A, Giupponi A, Brambillasca P, Lussana F, Pisano M, Goisis G, Bonacina D, Fazzi F, Naspro R, Longhi L, Cereda M, Montaguti C. At the epicenter of the Covid-19 pandemic and humanitarian crises in Italy: Changing perspectives on preparation and mitigation. NEJM Catalyst | March 21, 2020 https://doi.org/10.1056/CAT.20.0080 Available from:

https://catalyst.nejm.org/doi/full/10.1056/CAT.2 0.0080? fbclid=IwAR1LWoRq5zIomshBBugfp6 n0W-n_6TI90VJndf-YYMgGoiRD-

FmS2hPH8fo
2. Seshadri MS, John TJ. COVID-19 pandemic:

Defining the clinical syndrome and describing an empirical response. Christian Journal for Global Health 7(2); April 2020.

https://doi.org/10.15566/cjgh.v7i1.365

3. Guo L, Ren L, Yang S, Xiao M, Chang D, Yang F, Dela Cruz CS, Wang Y, Wu C, Xiao Y, Zhang L, Han L, Dang S, Xu Y, Yang Q, Xu S, Zhu H, Xu Y, Jin Q, Sharma L, Wang L, Wang J. Profiling early humoral response to diagnose novel coronavirus disease (COVID-19). Clinical Infectious Diseases, ciaa310. 2000 March 21. https://doi.org/10.1093/cid/ciaa310 Available from: https://academic.oup.com/cid/advancearticle-abstract/doi/10.1093/cid/ciaa310/5810754

4. Raoult D, Zumla A, Locatelli F, Ippolito G, Kroemer G. Coronavirus infections: Epidemiological, clinical and immunological features and hypotheses. Cell Stress 4(4); 3 Feb 2020: 66-74.

https://doi.org/10.15698/cst2020.04.216

Competing Interests: None declared.

Correspondence: Dr. Seshadri, India. mandalam.seshadri@gmail.com

Cite this article as: Seshadri Seshadri MS, John TJ. Hospital readiness for COVID-19: The scenario from India with suggestions for the world. Christian Journal for Global Health. April 2020;7(1):33-36. https://doi.org/10.15566/cjgh.v7i1.375

(C) Authors This is an open-access article distributed under the terms of the Creative Commons Attribution License, which permits unrestricted use, distribution, and reproduction in any medium, provided the original author and source are properly cited. To view a copy of the license, visit http://creativecommons.org/licenses/by/4.0/ 